\title{
Suicide in the 12 months after discharge from psychiatric inpatient care, Scotland 1968-92
}

\author{
John R Geddes, Ed Juszczak, Fiona O’Brien, Stephen Kendrick
}

\begin{abstract}
Study objective-To investigate the rate of suicide in the 12 months after discharge from psychiatric hospital and to determine its relationship to age, diagnosis, and period.

Design-Cohort study of patients discharged from psychiatric hospital.

Setting-Scotland.

Participants- Altogether 159742 men and 178271 women, aged 15-84, who were discharged from Scottish psychiatric hospitals during 1968-92.

Main results-During the 25 year period, 1212 male patients committed suicide in 198059 person years at risk (612 per 100 000; 95\% confidence interval (CI) 578, 647) and 1099 female patients committed suicide in 228993 person years at risk (480 per 100000 ; $95 \%$ CI 452, 509). The overal standardised mortality ratio (general population rate $=1)$ was $27(95 \%$ CI 26,29$)$ in men and $40(95 \% \mathrm{CI} 38,43)$ in women. There were variations in the suicide rates in relation to age, diagnosis, and period. The ratio of the 1-28 day rate to the rate between days 29 and 365 over the whole study period was $1.7(95 \%$ CI $1.4,1.9)$ in men and $1.6(95 \%$ CI $1.3,1.8)$ in women. Conclusions-The variations in the post discharge suicide rate by age, sex, diagnosis, geographical location, and period suggest that there are several risk factors which vary in their distribution. Further study of these may lead to the development of effective interventions.
\end{abstract}

(f Epidemiol Community Health 1997;51:430-434)

Patients are at increased risk of suicide after discharge from psychiatric hospital, especially in the first 28 days. ${ }^{1}$ The identification of this high risk period is important because, by intervening at this stage, it may be possible to prevent some of these suicides and, by doing so, contribute towards meeting the Health of the Nation target of a $33 \%$ reduction in suicide rates among the severely mentally ill. ${ }^{2}$ However, at the moment there are no interventions of known effectiveness for preventing suicide. ${ }^{3}$ In order to develop and evaluate interventions which may do this, more information is needed about the epidemiology of suicide after discharge from psychiatric hospital and of possible risk factors. Conventional risk factors may not be associated with suicide in these patients. ${ }^{4}$

We report the descriptive epidemiology of suicide occurring within 12 months of discharge from psychiatric hospital in Scotland between 1968 and 1992. This is an extension of a previous paper in which we described period trends in the rate of suicide within 28 days of discharge during the same period. ${ }^{5}$ The greater number of suicides that occur within 12 months of discharge provides more power to investigate variations in the rates in relation to age, sex, diagnosis, and period. We also compared the Scottish post-discharge suicide rates with those reported in Oxford.

Methods

SUBJECTS

We conducted a retrospective cohort study of patients, aged 15-84 years, who were discharged from psychiatric inpatient care in Scotland between 1968 and 1992. We obtained data from the file linking the Scottish morbidity record scheme for psychiatric inpatients and the death register of the General Register Office for Scotland. ${ }^{6}$ Diagnoses on this scheme are coded according to the 9th revision of the International Classification of Diseases. ${ }^{7}$ Discharge diagnoses were grouped into seven categories: schizophrenia (ICD-9 295), nonpsychotic depression (300.4 and 311), affective psychosis (296), non-depressive neuroses (300, except 300.4), alcohol dependence (303), personality disorder (301), and other diagnoses. Deaths coded as suicide and self inflicted injury (E950-959) or injury undetermined whether accidentally or purposely inflicted (E980-989) were classed as suicide.

\section{COMPARISON WITH GENERAL POPULATION}

RATES

We assumed that patients discharged from psychiatric hospital were exposed to the same risk factors for suicide as the general population as well as the increase in risk associated with being a psychiatric patient. Scottish population suicide rates have fallen slightly in women between 1968 and 1992 and increased substantially in young men. ${ }^{8}$ We took account of the changes in the suicide rate in the general population by using the national rates for each time period and calculating the standardised mortality ratio (SMR) (relative to a baseline general population rate of 1 ) by the indirect method. ${ }^{9}$

\section{CALCULATION OF THE DENOMINATOR}

The time at risk was calculated as the time from discharge to death, subsequent readmission, or the end of the risk period of 12 months. When a patient had more than one hospital admission, 
he was deemed to be at risk after discharge for the period following the first discharge. He would then be at risk again, after the next discharge, with the calculation of a second and separate period of risk starting from the day after the second discharge. The study period was divided into five year periods and the period at risk for each subject, stratified by age and diagnosis, was allocated to the appropriate period. The denominator for each five year period comprised the total person-years at risk. Suicide rates within 12 months of discharge per 100000 person-years at risk were calculated using the person-years program. ${ }^{10}$

\section{STATISTICAL ANALYSIS}

We performed separate analyses for males and females because of the sex differences in the population suicide rates. We used Poisson regression to estimate the mortality ratio of the risk of suicide after hospital discharge, using the software GLIM and EGRET. ${ }^{112}$ This allowed the examination of the effect of age, diagnosis, and period and investigation of the presence of first order interactions.

The regression analysis was performed twice with both the person-years of observation and the expected number of suicides (calculated on the basis of age and sex specific Scottish population rates) as the rate multiplier. We modelled the effect of period on suicide rates both within the study cohort and adjusting for the trends in suicide rates in the general population. We performed a test for a trend in the estimated period effect. To allow a comparison with the findings of Goldacre $e t$ al we calculated the ratio of the rate of suicide in the first 28 days after discharge compared with that between days 29-365. ${ }^{1}$

\section{INTERPRETATION OF PERIOD TRENDS}

The interpretation of trends in standardised suicide rates and within cohort rates can be difficult, especially when there are period trends in the background national rates. There are four possible combinations:

- A trend in the same direction (or the absence of a trend) in both standardised rates and within cohort rates. This situation is the most likely to represent a true trend (or the absence of a trend) in the risk of suicide in patients after discharge from psychiatric hospital, even after taking trends in the general population into account.

- A trend in the within cohort rate with no trend in the same direction in the standardised rate. This situation represents an apparent change in the risk of suicide associated with discharge, which is probably due to the changing risk of suicide in the general population.

- No trend in the within cohort rate with a trend in the standardised rates. This situation represents a stable risk associated with discharge in the presence of a changing population suicide rate. The attributable risk of suicide associated with discharge from hospital would therefore be changing.

\section{KEY POINTS}

- Between 1968 and 1992, suicide rates in patients within 12 months of discharge from Scottish psychiatric hospitals were very high compared with rates in the general Scottish population-27 times higher in men and 40 times higher in women.

- Significant variations in the suicide rates in relation to age, diagnosis, and period may help us to develop and evaluate interventions to prevent suicide.

- A trend in the within cohort rate with an opposite trend in the standardised rate. This possibility would be the most difficult to interpret and would be likely to represent a situation in which post-discharge rates and population rates of suicide were largely independent and being affected by heterogeneous factors.

\section{Results}

Between 1968 and 1992 there were 1212 male suicides within 12 months of discharge in 198059 person-years at risk and 1099 female suicides in 228993 person-years at risk. The overall suicide rate was 612 per $100000(95 \%$ confidence interval (CI) 578, 647) personyears at risk in men and 480 per 100000 (452, 509 ) person-years at risk in women. The overall SMR (general population rate $=1$ ) was 27 $(95 \%$ CI 26,29$)$ in men and $40(38,43)$ in women. The observed number of suicides within 12 months of discharge, person-years at risk, suicide rate per 100000 person-years observation, and SMR are shown in relation to age group and period in table 1 and in relation to diagnosis in table 2 . Approximately $16 \%$ of patients who committed suicide within the 12 months of hospital discharge did so within the first 28 days. The ratio of the 1-28 day rate to the rate between days 29 and 365 over the whole study period was 1.7 (95\% CI $1.4,1.9)$ in men and $1.6(1.3,1.8)$ in women. There was no apparent trend in this ratio during the period.

Although we found that the rate of suicide was significantly increased in the first 28 days compared with the rate between days 29 and 365 , the rate ratio was smaller than that reported by Goldacre et al in Oxford, where the rate ratios were 5.2 in males and 3 in females. ${ }^{1}$ The $95 \%$ CIs of these estimates exclude those of our own. Further examination of these rates reveals that the difference is due to significantly lower rates of suicide in the first 28 days after discharge in Scotland, although the rates during the remainder of the 12 month period are very similar.

\section{RELATIVE RISK BY DIAGNOSIS}

The overall SMR for suicide in the first 12 months was high compared with the general Scottish population and there was heterogeneity in the rates for patients with different 
Table 1 Suicide rates within cohort during 12 months after hospital discharge and standardised mortality ratios (SMR) in Scotland, 1968-92, in relation to age, sex, and five year period. SMRs are expressed using the general population rate $=1$.

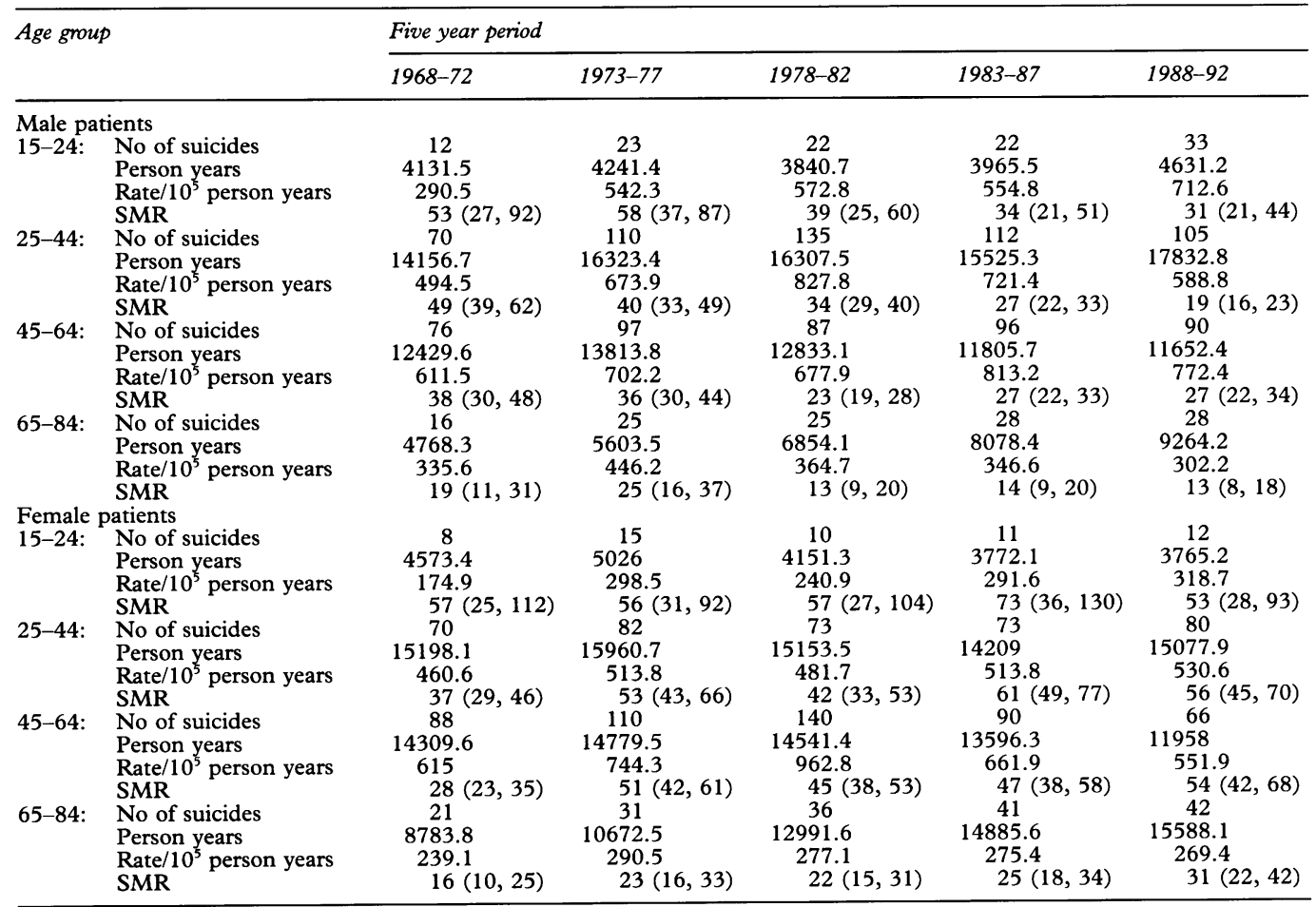

Table 2 Suicide rates within cohort during 12 months after hospital discharge and standardised mortality ratios (SMR) in Scotland, 1968-1992, in relation to sex and diagnosis. Values in parentheses are $95 \%$ confidence intervals unless stated otherwise

\begin{tabular}{|c|c|c|c|c|c|}
\hline Diagnosis (ICD-9 code) & $\begin{array}{l}\text { Observed no } \\
\text { of suicides }\end{array}$ & $\begin{array}{l}\text { Person } \\
\text { years }\end{array}$ & $\begin{array}{l}\text { Rate } 100000 \\
\text { person years }\end{array}$ & $\begin{array}{l}S M R \\
(95 \% C I)^{*}\end{array}$ & Rate ratio \\
\hline \multicolumn{6}{|l|}{ Male patient: } \\
\hline Schizophrenia (295) & 184 & 28837.8 & 638.1 & $29(25,34)$ & 1 \\
\hline Non-psychotic depression $(300.4,311)$ & 200 & 19643.1 & 1018.2 & $47(41,54)$ & $1.63(1.34,2.00)$ \\
\hline Affective psychoses (296) & 183 & 22313.2 & 820.1 & $35(30,41)$ & $1.29(1.05,1.59)$ \\
\hline Non-depressive neuroses (300 except 300.4) & 41 & 6450.7 & 635.6 & $32(23,43)$ & $1.02(0.73,1.44)$ \\
\hline Alcohol dependence (303) & 298 & 53965.3 & 552.2 & $24(21,27)$ & $0.81(0.67,0.97)$ \\
\hline Personality disorder (301) & 107 & 14398.4 & 743.1 & $40(33,49)$ & $1.22(0.96,1.56)$ \\
\hline Other & 199 & 52450.8 & 379.4 & $17(14,19)$ & $0.70(0.57,0.85)$ \\
\hline Total & 1212 & 198059.2 & 611.9 & $27(26,29) \ddagger$ & \\
\hline \multicolumn{6}{|l|}{ Female patient: } \\
\hline Schizophrenia (295) & 99 & 23931.5 & 413.7 & $34(28,41)$ & \\
\hline Non-psychotic depression $(300.4,311)$ & 299 & 46094.1 & 648.7 & $52(47,59)$ & $1.60(1.27,2.00)$ \\
\hline Affective psychoses (296) & 245 & 49623.0 & 493.7 & $37(33,42)$ & $1.15(0.91,1.46)$ \\
\hline Non-depressive neuroses (300 except 300.4 ) & 64 & 12120.1 & 528.1 & $44(35,56)$ & $1.32(0.96,1.80)$ \\
\hline Alcohol dependence (303) & 111 & 17213.8 & 644.8 & $49(41,59)$ & $1.39(1.06,1.83)$ \\
\hline Personality disorder (301) & 106 & 14980.5 & 707.6 & $73(60,88)$ & $2.04(1.54,2.69)$ \\
\hline Other & 175 & 65030.5 & 269.1 & $25(21,29)$ & $0.86(0.67,1.11)$ \\
\hline Total & 1099 & 228993.4 & 479.9 & $40(38,43) \ddagger$ & \\
\hline
\end{tabular}

* General population rate $=1$

+ Schizophrenia as baseline, adjusted for the confounding effects of age and period.

$\ddagger$ Overall crude standardised mortality ratio.

discharge diagnoses. The rate ratios in relation to diagnosis are shown in table 2 , in which the rate for schizophrenia (ICD9 295) is taken as the baseline. Schizophrenia was chosen as the baseline because it is a disorder which still requires frequent hospital treatment and also because the Health of the Nation target of a $33 \%$ reduction in suicide among the severely mentally ill refers to schizophrenia. ${ }^{13}$ The rate of suicide within 12 months of discharge was generally higher in diagnoses other than schizophrenia. It was significantly higher in male patients with a discharge diagnosis of nonpsychotic depression and affective psychoses and in female patients with diagnoses of nonpsychotic depression, alcohol dependence, and personality disorder. The rate was significantly lower in male patients with diagnoses of alcohol dependence.

PERIOD TRENDS

In female patients there was a statistically significant interaction between the terms for period and diagnosis $(p=0.03)$. Therefore we calculated age adjusted, diagnosis specific relative risk estimates for the effect of period (table 3). There was no significant period interaction in male patients and so we calculated age and diagnosis adjusted relative risk estimates for the effect of period (table 4). 
Table 3 Diagnosis specific within cohort and externally standardised mortality ratios (SMR) for the effect of period on suicide after discharge from psychiatric hospital in female patients, Scotland, 1968-92

\begin{tabular}{|c|c|c|c|c|c|c|c|}
\hline & \multirow{2}{*}{$\begin{array}{l}\text { Five year } \\
\text { period }\end{array}$} & \multicolumn{6}{|c|}{ Diagnosis (ICD-9 code) } \\
\hline & & $\begin{array}{l}\text { Schizophrenia } \\
\text { (295) }\end{array}$ & $\begin{array}{l}\text { Affective psychosis } \\
\text { (296) }\end{array}$ & $\begin{array}{l}\text { Non-depressive } \\
\text { neurosis ( } 300)\end{array}$ & $\begin{array}{l}\text { Non-psychotic depression } \\
(300.4,311)\end{array}$ & $\begin{array}{l}\text { Personality disorder } \\
\text { (301) }\end{array}$ & $\begin{array}{l}\text { Alcohol dependence } \\
\text { (303) }\end{array}$ \\
\hline $\begin{array}{l}\text { Within cohort mortality } \\
\text { ratio* } \\
\text { Test for trend }\end{array}$ & $\begin{array}{l}1968-72 \\
1973-77 \\
1978-82 \\
1983-87 \\
1988-92 \\
\text { p value }\end{array}$ & $\begin{array}{l}1 \\
2.1 \\
1.3 \\
1.7 \\
1.2 \\
0.874\end{array}$ & $\begin{array}{l}1 \\
1.7 \\
2.0 \\
1.4 \\
1.6 \\
0.254\end{array}$ & $\begin{array}{l}1 \\
1.2 \\
2.5 \\
2.4 \\
2.2 \\
0.024\end{array}$ & $\begin{array}{l}1 \\
1.0 \\
1.2 \\
1.3 \\
1.1 \\
0.338\end{array}$ & $\begin{array}{l}1 \\
1.0 \\
0.9 \\
1.3 \\
0.9 \\
0.826\end{array}$ & $\begin{array}{l}1 \\
1.1 \\
0.9 \\
0.6 \\
0.9 \\
0.201\end{array}$ \\
\hline $\begin{array}{l}\text { Externally standardised } \\
\text { mortality ratio* } \\
\text { Test for trend }\end{array}$ & $\begin{array}{l}1968-72 \\
1973-77 \\
1978-82 \\
1983-87 \\
1988-92 \\
\text { p value }\end{array}$ & $\begin{array}{l}1 \\
2.7 \\
1.4 \\
2.5 \\
1.7 \\
0.181\end{array}$ & $\begin{array}{l}1 \\
2.3 \\
2.1 \\
2.0 \\
2.7 \\
0.001\end{array}$ & $\begin{array}{l}1 \\
1.6 \\
2.6 \\
3.2 \\
3.6 \\
<0.001\end{array}$ & $\begin{array}{l}1 \\
1.4 \\
1.2 \\
1.8 \\
1.8 \\
<0.001\end{array}$ & $\begin{array}{l}1 \\
1.3 \\
0.9 \\
1.8 \\
1.3 \\
0.269\end{array}$ & $\begin{array}{l}1 \\
1.5 \\
1.0 \\
0.9 \\
1.4 \\
0.811\end{array}$ \\
\hline
\end{tabular}

* Adjusted for the confounding effect of age. With person years at risk as offset. With expected number of suicides derived from national rates as offset.

Table 4 Mortality ratios within cohort and externally standardised mortality ratios for effect of period on suicide after discharge from psychiatric hospital in male patients (all diagnoses), Scotland, 1968-92. Values in parentheses are 95\% confidence intervals unles stated otherwise

\begin{tabular}{lcc}
\hline Five year period & $\begin{array}{l}\text { Within cohort mortality } \\
\text { ratio }\end{array}$ & $\begin{array}{l}\text { Externally standardised } \\
\text { mortality ratio }\end{array}$ \\
\hline $1968-72$ & 1 & 1 \\
$1973-77$ & $1.36(1.12,1.65)$ & $0.99(0.81,1.20)$ \\
$1978-82$ & $1.49(1.23,1.80)$ & $0.72(0.59,0.87)$ \\
$1983-87$ & $1.47(1.21,1.78)$ & $0.68(0.56,0.82)$ \\
$1988-92$ & $1.34(1.11,1.63)$ & $0.57(0.47,0.69)$ \\
Deviance (df) & $273.7(228)$ & $284.1(228)$ \\
Likelihood ratio statistic (df) & $7.75(1)$ & $48.83(1)$ \\
p value & 0.005 & $<0.0001$ \\
\hline
\end{tabular}

* Adjusted for confounding effects of age and diagnosis. With person years at risk as offset. With expected number of suicides derived from national rates as offset.

There were significant increases in the externally SMR, with no increase in the within cohort mortality ratio, in female patients with discharge diagnoses of affective psychosis and non-psychotic depression. The only patients with a significant increase in both the within cohort (trend test $p=0.024$ ) and the externa SMRs (trend test $\mathrm{p}=0.001$ ) were those with a discharge diagnosis of non-depressive neuroses in whom the SMR was $3.55(95 \%$ CI 1.45 , $8.74)$ times higher in the last five year period than in the first.

In male patients there was an increasing linear trend in period effect on the within cohort mortality ratio $(p=0.005)$ but a decreasing linear trend in period effect on the externally SMR ( $p<0.0001)$. The SMR in male patients was $43 \%$ lower in the last five year period than in the first five (SMR 0.57; 95\% CI 0.47, 0.69). The within cohort mortality ratio was $34 \%$ higher in the last five year period than in the first (SMR 1.34; 95\% CI 1.11, 1.63).

\section{Discussion}

The use of a large national data set provided sufficient data to allow us to investigate variations in the suicide rate after hospital discharge in relation to age, sex, diagnosis, and period. However, routinely collected observational data are subject to a number of biases. ${ }^{14}$ For example, misclassification of discharge diagnosis and the distinction between first admission and readmission has been reported in the data set used in this study and diagnostic practice may have changed over time. ${ }^{1516}$ The definition of suicide used in this study may have introduced misclassification, although we followed recognised practice by using codes E950-9 and E980-9. ${ }^{17}$ Furthermore, we could only examine a limited number of variables: it is possible that residual confounding exists which we were unable to detect. Interpretation of our findings must therefore be cautious.

Although all patients had a greatly increased rate of suicide compared with the general population, there were variations in the rates between subgroups. In both sexes, most suicides occurred in those aged between 25 and 64 years. However, the rate of suicide was also high in the 15-24 year age group, reflecting the smaller number of person-years. Patients of either sex with a diagnosis of non-psychotic depression, and women with a diagnosis of personality disorder were at significantly greater risk of suicide in the 12 months after discharge than patients with schizophrenia.

In women, with the exception of patients with a discharge diagnosis of non-depressive neurosis, there were no within cohort trends, although there were significant trends in the standardised mortality rates. This would fit with the third trend combination referred to above. There has generally been a constant rate of suicide within 12 months of discharge in female patients together with a declining population rate. Suicide in discharged female patients therefore accounts for an increasing proportion of suicides in the total female population. Interpreting the results of this and our previous study together, the increasing trend in suicide rates in female patients may be restricted to the early period after discharge home. ${ }^{5}$

In men, there was a significant increasing trend in suicide rates within the cohort which was mirrored in the trend we found in the 28 day rates (although that was not statistically significant). In addition, the significantly decreasing period trend in the standardised rates was very similar at 28 days and 12 months. Opposing period trends in the within cohort and externally standardised mortality rates is the fourth possible combination we identified above. Our interpretation is that there has been a small increase in the rate of post discharge suicide in male patients which has not been confined to the early period after discharge. It 
has occurred in the presence of a much larger increase in the rate of suicide in the general male population, particularly in young men, who are unlikely to be admitted to psychiatric hospital. ${ }^{18}$

Although the suicide rate was higher in the first month after discharge than in the subsequent 11 months, the difference was less marked than that reported from Oxford. ${ }^{1} \mathrm{Al}-$ though the difference in early post discharge rates between Oxford and Scotland is intriguing, we are unable adequately to explain this using the current data. It could be due to variations in social factors as well as the delivery of care and possible differences in the reporting of suicide.

Together with the variations in the rate of suicide in relation to age and diagnosis, the difference between Oxford and Scotland suggests that a range of factors may be related to the rate of suicide after discharge from psychiatric hospital. These factors need further study as some of them may be modifiable. Observational data such as those presented in this paper have sometimes been suggested as health outcome indicators. ${ }^{1920}$ We suggest that this is unjustified both because of the limited knowledge of the risk factors for suicide after discharge and also the absence of effective interventions for reducing suicide. $^{3}$

We thank James Boyd, Scott Fleming, and Mary Smalls of ISD for their help with this study. We are indebted to Alison Douglas for their help with this study. We are indebted to Alison for advising on the use of the person-years program. Funding: Chief Scienth

Conflict of interest: none
1 Goldacre M, Seagroatt V, Hawton K. Suicide after discharge from psychiatric inpatient care. Lancet 1993;342: 283-86.

2 Department of Health. The health of the nation. London: HMSO, 1992

3 Gunnell D, Frankel S. Prevention of suicide: aspirations and evidence. $B M \mathcal{F}$ 308: 1227-33, 1994.

4 Dennehy JA, Appleby L, Thomas CS, Faragher EB. Casecontrol study of suicide by discharged psychiatric patients. $B M F$ 1996;312: 1580 .

5 Geddes JR, Juszczak E. Period trends in rate of suicide in first 28 days after discharge from psychiatric hospital in Scotland, 1968-92. BMF 1995;311: 357-60.

6 Kendrick S, Clark J. The Scottish record linkage system. Health Bull (Edinb) 1993;51: 72-79.

7 World Health Organization. Mental disonders: glossary and guide to their classification in accordance with the ninth revision of the International Classification of Diseases (ICD-9). Geneva: WHO, 1978

8 Kreitman N. Suicide in Scotland, with special reference to youth. Health Bull (Edinb) 1994;52: 300-9.

9 Clayton D, Hills M. Statistical methods in epidemiology. Oxford: Oxford University Press, 1993.

10 Coleman M, Douglas A, Hermon C, Peto J. Cohort study analysis with a FORTRAN computer program. Int $\mathcal{f} E p$ demiol 1986;15: 134-37.

11 Baker RJ, Nelder JA. The GLIM system. Release 3.77. Oxford: Numerical Algorithms Group, 1978.

12 Statistics and Epidemiology Research Corporation. EGRET. Epidemiological graphics, estimation and testing. Seattle: Statistics and Epidemiology Research Corporation, 1991.

13 Department of Health. The health of the nation. Key area handbook: mental illness. London: HMSO, 1994.

14 Naylor CD, Guyatt GH. Users guides to the medical literature. $\mathrm{X}$. How to use an article reporting variations in the outcomes of health services. The Evidence-Based Medicine Working Group. $¥ A M A$ 1996;275: 554-58.

15 McGonigal G, McQuade C, Thomas B. Accuracy and completeness of Scottish mental hospital in-patient data Health Bull (Edinb) 1992;50: 309-14.

16 Geddes JR, Black RJ, Whalley LJ, Eagles JM Decline in the diagnosis of schizophrenia. Br $\mathcal{F}$ Psychiatry 1994;164: $564-65$.

17 Kreitman N. Suicide in Scotland, with special reference to youth Health Bull (Edinb) 1994; 52: 300-9

18 Vassilas CA, Morgan HG. General practitioners' contact with victims of suicide. $B M 7$ 1993;307: 300-1.

19 Jenkins R. Towards a system of outcome indicators for mental health care. Br f Psychiatry 1990;157: 500-14.

20 Scottish Office. Clinical Outcomes Working Group: clinical outcome indicators. Edinburgh: HMSO, 1994 